\title{
New aspects of an old drug: metformin as a glucagon-like peptide 1 (GLP-1) enhancer and sensitiser
}

\author{
Y. M. Cho • T. J. Kieffer
}

Received: 30 September 2010 / Accepted: 22 October 2010/Published online: 30 November 2010

(C) Springer-Verlag 2010

\begin{abstract}
The two major deficits in type 2 diabetes, insulin resistance and impaired beta cell function, are often treated with metformin and incretin-based drugs, respectively. However, there may be unappreciated benefits of this combination of therapies. In this issue of Diabetologia, Maida et al. (doi:10.1007/s00125-010-1937-z) report that metformin acutely increases plasma levels of glucagon-like peptide 1 (GLP-1) in mice. Moreover, they show that metformin enhances the expression of the genes encoding the receptors for both GLP-1 and glucose-dependent insulinotropic polypeptide (GIP) in mouse islets and also increases the effects of GIP and GLP-1 on insulin secretion from beta cells. Interestingly, these incretin-sensitising effects of metformin appear to be mediated by a peroxisome proliferator-activated receptor $\alpha$-dependent pathway, as opposed to the more commonly ascribed pathway of metformin action involving AMP-activated protein kinase. These provocative findings by Maida et al. extend our understanding of the mechanism of action of metformin and provide further insights into the benefits of combining metformin with incretin-based drugs to combat diabetes.
\end{abstract}

Keywords Dipeptidyl peptidase-4 · Glucagon-like peptide 1 . Incretin · Metformin · Type 2 diabetes

\footnotetext{
Y. M. Cho $\cdot$ T. J. Kieffer $(\bowtie)$ Life Sciences Centre, University of British Columbia, Vancouver, BC, Canada V6T 1Z3

e-mail: tim.kieffer@ubc.ca

Y. M. Cho

Department of Internal Medicine,

Seoul National University College of Medicine,

Seoul, South Korea
}

Laboratory of Molecular and Cellular Medicine, Department of Cellular and Physiological Sciences, 2350 Health Sciences Mall,

\author{
Abbreviations \\ AMPK AMP-activated protein kinase \\ DPP-4 Dipeptidyl peptidase-4 \\ GIP Glucose-dependent insulinotropic polypeptide \\ GLP-1 Glucagon-like peptide 1 \\ $\operatorname{PPAR} \alpha \quad$ Peroxisome proliferator-activated receptor $\alpha$
}

For more than 50 years metformin has been used to control hyperglycaemia in patients with type 2 diabetes, and it is currently recommended as the first-line drug treatment along with lifestyle modification [1]. Furthermore, metformin can dramatically reduce the incidence of type 2 diabetes in individuals with impaired glucose tolerance who are at high risk of developing type 2 diabetes [2]. Metformin is thought to exert these powerful effects primarily by counteracting insulin resistance to curtail hepatic glucose output and increase insulin-stimulated glucose uptake in muscle and fat [3]. Given that the two major defects in type 2 diabetes are insulin resistance and impaired insulin secretion, metformin is recommended for use in combination with insulin secretogogues and even with intensive insulin therapy [1]. Metformin is now increasingly being used in combination with new incretin-based therapies: glucagon-like peptide 1 (GLP-1) analogues and dipeptidyl peptidase-4 (DPP-4) inhibitors [4-6], both of which enhance pancreatic beta cell function. Interestingly, there have been a few reports suggesting a direct interaction between metformin and the incretin axis [7-9]. In this regard, the article by Maida et al. published in this issue of Diabetologia [10] provides new insights into the biological actions of metformin that improve glucose homeostasis.

Maida et al. [10] reported that metformin acutely and selectively increased plasma levels of GLP-1 in mice, even in the absence of concomitant oral glucose administration, 
while it did not increase plasma levels of the other incretin hormone, glucose-dependent insulinotropic polypeptide (GIP), or, curiously, peptide YY, a gastrointestinal hormone co-localised with GLP-1 in L cells. Therefore, the action of metformin on the gut endocrine system may be L cellspecific and, more precisely, GLP-1-specific. However, in a preliminary study [11], metformin did not increase GLP-1 secretion from $\mathrm{L}$ cells in vitro. Therefore, there appear to be as yet unknown pathways by which metformin can acutely increase GLP-1 secretion. In this regard, it is noteworthy that metformin increases intestinal glucose utilisation [3], which perhaps could be coupled to GLP-1 production. Moreover, it has recently been reported that metformin inhibits the apical sodium-dependent bile acid transporter and thus may increase the concentration of bile acids in the intestine [12], which could stimulate GLP-1 secretion from $\mathrm{L}$ cells via the G-protein-coupled receptor TGR5 [13]. Alternatively, DPP-4 activity might be inhibited by metformin, resulting in an increase in GLP-1 levels in the plasma. Indeed, DPP-4 activity in the circulation has been reported to be reduced in rodents or humans treated with metformin $[14,15]$. Yet, contrary to these findings, metformin does not directly inhibit DPP-4 activity in vitro $[9,14,16]$. Maida et al. [10] also found that metformin at doses exhibiting GLP-1increasing effects exerted no effect on plasma DPP-4 activity in mice. Furthermore, metformin increased plasma GLP-1 levels in rats genetically lacking DPP-4 [9]. Therefore, decreased DPP-4 activity is unlikely to explain the elevated GLP-1 levels after metformin treatment. The ability of metformin to increase GLP-1 levels independently of effects on DPP-4 suggests there could be a direct benefit in terms of incretin action by combining metformin with DPP-4 inhibitors. Indeed, the combination of a DPP-4 inhibitor with metformin provides substantial and additive glycaemic improvement compared with metformin alone in patients with type 2 diabetes [17, 18].

Type 2 diabetes is characterised by a relentless decline in pancreatic beta cell function over time. The UK Prospective Diabetes Study (UKPDS) suggested that the rate of beta cell deterioration associated with metformin was similar to that associated with diet alone or sulfonylureas [19]. However, in A Diabetes Outcome Progression Trial (ADOPT), metformin exhibited a reduced risk of monotherapy failure compared with the sulfonylurea glibenclamide (known as glyburide in the USA and Canada) and slower rate of loss of beta cell function, although it was inferior to the thiazolidinedione rosiglitazone [20]. Metformin has also been shown to improve insulin secretion from rat islets chronically exposed to high levels of NEFA or glucose [21], suggesting a direct effect on pancreatic beta cells indepen-
Fig. 1 The proposed mechanisms of metformin action on glucose homeostasis. In addition to the known actions of metformin - suppressing hepatic glucose output, increasing glucose uptake in muscle and fat, and increasing glucose utilisation in the gut [3]metformin may enhance incretin signalling by increasing the plasma level of GLP-1 from L cells (red) but not GIP from $\mathrm{K}$ cells (blue), as well as by increasing the expression of GLP-1 and GIP receptors (GLP-1R and GIPR) in the insulin (yellow)-containing pancreatic beta cells via a $\operatorname{PPAR} \alpha$-dependent mechanism

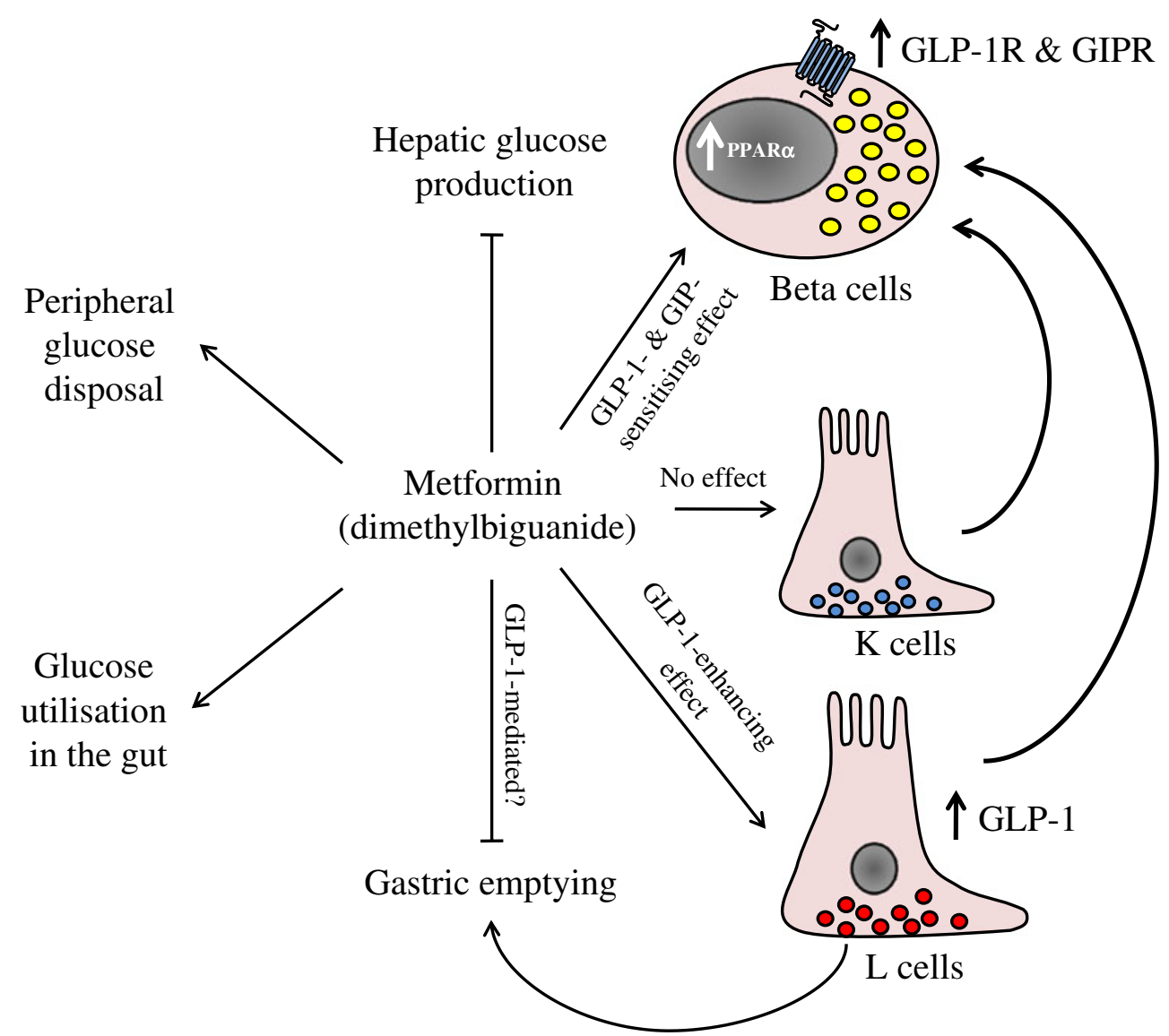


dent of its glucose-lowering action. What is the mechanism of these effects of metformin on pancreatic beta cells? Interestingly, Maida et al. [10] showed that metformin enhanced the expression of the genes encoding the receptors for both GIP and GLP-1 (Gipr and Glp1r, respectively) in mouse islets and also increased the effects of GIP and GLP-1 on insulin secretion from beta cells. While most of the actions of metformin appear to be mediated by cellular activation of AMP-activated protein kinase (AMPK), their findings indicate that the effects on incretin receptor expression in beta cells appear to be independent of AMPK, but, rather, are mediated by peroxisome proliferator-activated receptor $\alpha$ (PPAR $\alpha)$, as metformin failed to induce expression of the gene encoding the incretin receptor in islets from Ppar $\alpha$ knockout mice [10]. A PPAR $\alpha$-dependent mechanism was also found to regulate the expression of the Gipr in beta cells by glucose and fat [22]. Treatment of Otsuka Long Evans Tokushima Fatty (OLETF) rats, an obese animal model of type 2 diabetes, with the PPAR $\alpha$ agonist fenofibrate reduced the decline in beta cell mass and prevented the development of diabetes [23]. However, there appeared to be no additional glucose-lowering effect with the addition of fenofibrate to metformin therapy in humans $[24,25]$. Additional studies will be required to determine whether metformin can increase incretin receptor expression in human beta cells and thereby bolster incretin action in a meaningful way.

Although there are undoubtedly more details to unravel regarding the mechanisms of action of metformin, the work by Maida et al. [10] extends previous findings to indicate that metformin can be regarded as an enhancer of GLP-1 secretion and possibly as a GLP-1 sensitiser, beyond its known biological functions (Fig. 1). Certainly, the addition of a DPP-4 inhibitor to metformin therapy can boost GLP-1 levels much higher than the addition of a sulfonylurea [26]. Clinical studies have also indicated that metformin alone can increase GLP-1 levels, via a mechanism distinct from DPP-4 inhibition, and that combination therapy has a complementary effect on GLP-1 concentrations [27]. These findings suggest that a mechanism similar to that observed in mice [10] is at work in humans and that combining metformin with DPP-4 inhibitors appears to be a rational way of enhancing GLP-1 signalling in pancreatic beta cells. However, metformin-induced enhancement of incretin action does not appear to be a major mechanism by which metformin lowers blood glucose. Despite increased GLP-1 levels and incretin receptor expression on beta cells, the lower glucose levels achieved with metformin treatment were not associated with increased insulin levels [10]. Even more compelling is the finding that metformin essentially appeared to be as potent in lowering blood glucose levels in incretin receptor knockout mice as it did in wild-type mice. Given that the glucose-lowering effect of metformin is so strong and is independent of incretin signalling, it might be difficult to detect the beneficial effect of metformin on the incretin axis in human studies. Nonetheless, it would be interesting to examine whether or not metformin is able to reverse the decreased sensitivity of pancreatic beta cells to the insulinotropic effects of incretins associated with genetic polymorphisms in TCF7L2 [28-30] and WFS1 [31]. It just may be that there are still unappreciated benefits to the old drug, metformin.

Duality of interest The authors declare that there is no duality of interest associated with this manuscript.

\section{References}

1. Nathan DM, Buse JB, Davidson MB et al (2009) Medical management of hyperglycaemia in type 2 diabetes mellitus: a consensus algorithm for the initiation and adjustment of therapy: a consensus statement from the American Diabetes Association and the European Association for the Study of Diabetes. Diabetologia 52:17-30

2. Knowler WC, Barrett-Connor E, Fowler SE et al (2002) Reduction in the incidence of type 2 diabetes with lifestyle intervention or metformin. N Engl J Med 346:393-403

3. Bailey CJ, Turner RC (1996) Metformin. N Engl J Med 334:574-579

4. Amori RE, Lau J, Pittas AG (2007) Efficacy and safety of incretin therapy in type 2 diabetes: systematic review and meta-analysis. JAMA 298:194-206

5. Phung OJ, Scholle JM, Talwar M, Coleman CI (2010) Effect of noninsulin antidiabetic drugs added to metformin therapy on glycemic control, weight gain, and hypoglycemia in type 2 diabetes. JAMA 303:1410-1418

6. Pratley RE, Nauck M, Bailey T et al (2010) Liraglutide vs sitagliptin for patients with type 2 diabetes who did not have adequate glycaemic control with metformin: a 26-week, randomised, parallel-group, open-label trial. Lancet 375:1447-1456

7. Mannucci E, Ognibene A, Cremasco F et al (2001) Effect of metformin on glucagon-like peptide 1 (GLP-1) and leptin levels in obese nondiabetic subjects. Diabetes Care 24:489-494

8. Mannucci E, Tesi F, Bardini G et al (2004) Effects of metformin on glucagon-like peptide-1 levels in obese patients with and without type 2 diabetes. Diabetes Nutr Metab 17:336-342

9. Yasuda N, Inoue T, Nagakura T et al (2002) Enhanced secretion of glucagon-like peptide 1 by biguanide compounds. Biochem Biophys Res Commun 298:779-784

10. Maida A, Lamont BJ, Cao X, Drucker DJ (2011) Metformin regulates the incretin receptor axis via a peroxisome proliferatoractivated receptor alpha-dependent pathway in mice. Diabetologia. doi:10.1007/s00125-010-1937-z

11. Lauffer L, Grieco A, Iakoubov R, Brubaker PL (2009) Metformin activates the AMPK pathway and improves survival of murine and human L-cells but does not directly increase GLP-1 secretion. Diabetologia 52(Suppl 1):198, Abstract

12. Yao X, Chen L, McIntyre MS et al (2010) Biguanide antidiabetic agents increase fecal bile acids via inhibition of apical sodiumdependent bile acid transporter. Diabetes 59(Suppl 1):611-P, Abstract

13. Thomas C, Gioiello A, Noriega L et al (2009) TGR5-mediated bile acid sensing controls glucose homeostasis. Cell Metab 10:167-177

14. Lenhard JM, Croom DK, Minnick DT (2004) Reduced serum dipeptidyl peptidase-IV after metformin and pioglitazone treatments. Biochem Biophys Res Commun 324:92-97 
15. Lindsay JR, Duffy NA, McKillop AM et al (2005) Inhibition of dipeptidyl peptidase IV activity by oral metformin in type 2 diabetes. Diabet Med 22:654-657

16. Hinke SA, Kuhn-Wache K, Hoffmann T, Pederson RA, McIntosh $\mathrm{CH}$, Demuth HU (2002) Metformin effects on dipeptidylpeptidase IV degradation of glucagon-like peptide-1. Biochem Biophys Res Commun 291:1302-1308

17. Goldstein BJ, Feinglos MN, Lunceford JK, Johnson J, WilliamsHerman DE, Sitagliptin 036 Study Group (2007) Effect of initial combination therapy with sitagliptin, a dipeptidyl peptidase-4 inhibitor, and metformin on glycemic control in patients with type 2 diabetes. Diabetes Care 30:1979-1987

18. Ahren B, Pacini G, Foley JE, Schweizer A (2005) Improved mealrelated beta-cell function and insulin sensitivity by the dipeptidyl peptidase-IV inhibitor vildagliptin in metformin-treated patients with type 2 diabetes over 1 year. Diabetes Care 28:1936-1940

19. UK Prospective Diabetes Study Group (1995) U.K. prospective diabetes study 16 . Overview of 6 years' therapy of type II diabetes: a progressive disease. U.K. Prospective Diabetes Study Group. Diabetes 44:1249-1258

20. Kahn SE, Haffner SM, Heise MA et al (2006) Glycemic durability of rosiglitazone, metformin, or glyburide monotherapy. N Engl J Med 355:2427-2443

21. Patane G, Piro S, Rabuazzo AM, Anello M, Vigneri R, Purrello F (2000) Metformin restores insulin secretion altered by chronic exposure to free fatty acids or high glucose: a direct metformin effect on pancreatic beta-cells. Diabetes 49:735-740

22. Lynn FC, Thompson SA, Pospisilik JA et al (2003) A novel pathway for regulation of glucose-dependent insulinotropic polypeptide (GIP) receptor expression in beta cells. FASEB J 17:91-93

23. Koh EH, Kim MS, Park JY et al (2003) Peroxisome proliferatoractivated receptor (PPAR)- $\alpha$ activation prevents diabetes in
OLETF rats: comparison with PPAR- $\gamma$ activation. Diabetes 52:2331-2337

24. Pruski M, Krysiak R, Okopien B (2009) Pleiotropic action of short-term metformin and fenofibrate treatment, combined with lifestyle intervention, in type 2 diabetic patients with mixed dyslipidemia. Diabetes Care 32:1421-1424

25. Nieuwdorp M, Stroes ES, Kastelein JJ (2007) Normalization of metabolic syndrome using fenofibrate, metformin or their combination. Diabetes Obes Metab 9:869-878

26. Ahren B, Foley JE, Ferrannini E et al (2010) Changes in prandial glucagon levels after a 2-year treatment with vildagliptin or glimepiride in patients with type 2 diabetes inadequately controlled with metformin monotherapy. Diabetes Care 33:730732

27. Migoya EM, Bergeron R, Miller JL et al (2010) Dipeptidyl peptidase-4 inhibitors administered in combination with metformin result in an additive increase in the plasma concentration of active GLP-1. Clin Pharmacol Ther. doi:10.1038/clpt.2010.184

28. Lyssenko V, Lupi R, Marchetti P et al (2007) Mechanisms by which common variants in the TCF7L2 gene increase risk of type 2 diabetes. J Clin Invest 117:2155-2163

29. Shu L, Matveyenko AV, Kerr-Conte J, Cho JH, McIntosh CH, Maedler K (2009) Decreased TCF7L2 protein levels in type 2 diabetes mellitus correlate with downregulation of GIP- and GLP-1 receptors and impaired beta-cell function. Hum Mol Genet 18:2388-2399

30. Villareal DT, Robertson H, Bell GI et al (2010) TCF7L2 variant rs7903146 affects the risk of type 2 diabetes by modulating incretin action. Diabetes 59:479-485

31. Schäfer SA, Müssig K, Staiger H et al (2009) A common genetic variant in WFS1 determines impaired glucagon-like peptide-1induced insulin secretion. Diabetologia 52:1075-1082 